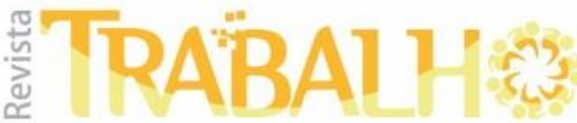 \\ (En)Cena
}

\section{O TRABALHO INFANTOJUVENIL EM OFICINAS MECÂNICAS E LAVA A JATOS NO TOCANTINS}

Child labor in mechanical workshops and carwashes in Tocantins

Travail des enfants dans les ateliers mécaniques et lavr-auto à Tocantins

El trabajo infanto-juvenil en talleres mecánicos y lavadeiros en Tocantins

Ana Cristina Serafim da Silva ${ }^{1}$

Professora do Curso de Psicologia da Universidade Federal do Tocantins, Graduada em Psicologia pela Universidade Federal da Paraíba, Mestrado e Doutorado em psicologia Social pela mesma Universidade. Líder do grupo de Estudo e Pesquisa sobre Infância e Adolescência.

\begin{abstract}
Resumo
O objetivo deste artigo é caracterizar o trabalho infantojuvenil em oficinas mecânicas e lava a jatos e a relação do trabalho com o processo de escolarização desses sujeitos. Participaram da pesquisa 18 crianças e adolescentes que trabalhavam em oficinas mecânicas e lava a jatos de uma cidade de pequeno porte no norte do Tocantins. Utilizou-se um questionário composto de questões abertas e fechadas, que contemplavam, entre outros aspectos, o perfil socioeconômico, nível de escolaridade e atividade. Para a análise, utilizou-se a estatística descritiva e o software SPSS. Os dados mostram que a idade dessas crianças e adolescentes variava de 11 à 17 anos, todos do sexo masculino, o que revela ser uma atividade cortada pelo viés do gênero, e $90 \%$ se declararam afrodescendentes. A maioria pertencem à famílias de classe baixa e que tem pouco incentivo à educação, $70 \%$ deles já tinham sido reprovados na escola. Metade dos participantes exerciam atividade em lava a jatos e os outros nas oficinas mecânicas, dentre as atividades que se destacam, lavar e encerar carros e troca de óleo e remendos de pneus de carros, motocicletas e bicicletas, entre outros.
\end{abstract}

Palavras-chave: trabalho infantojuvenil; oficinas mecânicas; Lava a jatos: escolarizacão.

\begin{abstract}
The purpose of this article is to characterize child labor in mechanical workshops and carwashes, and the relationship of this work with the school. The study included 18 children and adolescents who worked in mechanical workshops and washes of a small city in the north of Tocantins. A questionnaire was used to collect data, composed of open and closed questions, which included, among others, aspects such as socio-economic profile, schooling and activity. For the analysis, descriptive statistics and SPSS software were used. The data show that the age of these children and adolescents ranged from 11 to 17 years old, all of them male, which turns out to be an activity cut by gender bias, and $90 \%$ declared themselves to be of African descent. Most of them belong to the lower-class families and have little incentive to education, $70 \%$ of whom had already failed at school.
\end{abstract}

Keywords: child labor: mechanical workshops: lava jets: schooling.

\section{Rés umé}

Le but de cet article est de caractériser le travail des enfants dans les ateliers mécaniques et le lave-auto, et la relation de ce travail avec l'école. L'étude a inclus 18 enfants et adolescents qui travaillaient dans des ateliers mécaniques et des lavages d'une petite ville au nord de Tocantins. Un questionnaire a été utilisé pour collecter des données, composé de questions ouvertes et fermées, qui comprenaient, entre

${ }^{1}$ anacris serafim@uft.edu.br 
autres, des aspects tels que le profil socio-économique, la scolarité et l'activité. Pour l'analyse, des statistiques descriptives et un logiciel SPSS ont été utilisés. Les données montrent que l'âge de ces enfants et adolescents variait de 11 à 17 ans, tous des hommes, ce qui s'avère être une activité réduite par des préjugés sexistes, et $90 \%$ déclarent être d'origine africaine. La plupart d'entre eux appartiennent aux familles de la classe inférieure et ont peu d'incitation à l'éducation, 70\% d'entre eux ayant déjà été désapprouvés à l'école.

Mots-clés: travail des enfants; ateliers mécaniques; lave-auto;retard scolaire.

\section{Resumen}

El objetivo de este artículo es caracterizar el trabajo infanto-juvenil en talleres mecánicos y lavaderos, y la relación de ese trabajo con la escuela. Participaron de la investigación 18 niños y adolescentes que trabajaban en talleres mecánicos y lavaderos de una pequeña ciudad en el norte de Tocantins. Se utilizó un cuestionario para la recolección de datos, compuesto de cuestiones abiertas y cerradas, que contemplaban, entre otros, aspectos como perfil socioeconómico, escolaridad y actividad. Para el análisis, se utilizó la estadística descriptiva y el software SPSS. Los datos muestran que la edad de estos niños y adolescentes varía de 11 a 17 años, todos del sexo masculino, lo que revela ser una actividad cortada por el sesgo del género, y el $90 \%$ se declararon afrodescendientes. La mayoría pertenecen a familias de clase baja y que tienen poco incentivo a la educación, el $70 \%$ de ellos ya habían sido reprobados en la escuela.La mitad de los participantes ejercía la actividad em lavaderos y la otra parte en talleres mecánicos, realizando labores de lavar y encerar carros, câmbios de aceite y reparación de llantas de carro, motocicletas y bicicletas, entre otros.

Palabras clave: trabajo infantojuvenil; alleres mecánicos; Lavaderos; el desfase escolar.

\section{Introdução}

O objetivo deste artigo é caracterizar o trabalho infantojuvenil em oficinas mecânicas e lava a jatos e a relação do trabalho com o processo de escolarização desses sujeitos. Justifica-se a importância da temática, dado o alto número de crianças e principalmente adolescentes nesse tipo de atividade, além de permitir conhecer sobre o acesso desses jovens à escola, a defasagem escolar, permanência e desistência, bem como a pouca produção científica no que se refere a essa atividade de trabalho.

O trabalho infantojuvenil não é fato novo na história da humanidade, mas ganha evidência a partir da Revolução Industrial.
Com o aparecimento do comércio e da indústria, estabeleceu-se uma nova divisão de trabalho, simplificando tarefas, criando hierarquias, modificando funções, reservando espaços para aqueles que não tinham formação. Estas condições acabaram por favorecer a incorporação de crianças em diversos setores da produção (Ariès, 1995; Del Priore, 2007).

No Brasil, esse contexto de inserção de crianças e adolescentes no trabalho infantojuvenil também não é um fenômeno da contemporaneidade. Desde a época das Grandes Navegações, crianças e adolescentes eram recrutadas para serem "grumetes" e "pajens", ficando expostos também a abusos sexuais de marujos e/ou outros tripulantes, sofrendo privações 
alimentares e submetidos a trabalhos perigosos e exaustivos (Ramos, 2007).

Durante o regime escravista as crianças negras tinham uma infância que ia até os oito anos, assumindo várias funções laborais. Já se considerava adulto aos 14 anos (Góes \& Florentino, 2009). Ao fim desse regime, com a vinda de imigrantes para o Brasil e o grande êxodo rural, houve um aumento no número de crianças e adolescentes nas grandes cidades. Várias iniciativas surgiram para a preparação da mão de obra infantojuvenil. O trabalho era visto como um dos meios mais eficazes para reintegração da criança na sociedade (Santos, 2009).

As crianças e os adolescentes foram empregados tanto nas indústrias, como na agricultura, considerados mais rentáveis, devido aos baixos salários, e por serem mais "dóceis", sendo fácil controlar. Além do trabalho ser visto como antídoto àmarginalidade, permitia que essas crianças e adolescentes tivessem uma profissão e uma formação. Essas foram medidas adotadas pelo Estado para integração das crianças e adolescentes na sociedade, e isso se deu em decorrência desses sujeitos serem considerados ameaçadores à ordem vigente (Rizzini, 2009).

Várias propostas e políticas de formação colocavam o trabalho como sendo a solução para as classes populares, desde a Roda dos Expostos, Casa de Educandos e
Artífices, Institutos, escolas profissionais, patronatos agrícolas e escolas corretivas do período republicano, Escolas de Aprendizes Artífices (Pillotti \& Rizini, 2009). Esse processo continua durante os séculos $\mathrm{XX}$ e XXI com a presença de crianças e adolescentes pobres exercendo alguma atividade de trabalho, inclusive em situações degradantes, perigosas e penosas.

A partir da Constituição Federal de 1988, foi criado o Estatuto da Criança e do Adolescente (ECA), Lei n. 8.069/1990, cujo objetivo é efetivar a garantia dos direitos das crianças e dos adolescentes, considerando a especificidade do sujeito. São reconhecidos às crianças e aos adolescentes (de zero até os 18 anos) os Direitos Humanos reconhecidos a todos. Mas àqueles são acrescentados os decorrentes das especificidades da criança, em razão de sua maior vulnerabilidade e do fato de ainda estarem em processo de formação e desenvolvimento (Brasil, 2014). Contém nos seus artigos, entre tantos outros, a proibição do trabalho infantojuvenil, a proteção ao trabalhador adolescente e determina a forma de atuação das instituições que fazem parte da Rede de proteção, na prevenção e casos de violação dos direitos desses sujeitos. O ECA representa um avanço na legislação, muito mais que uma normativa, o ECA aparece como uma norma disciplinadora da teoria da proteção integral que previu um 
reordenamento político e institucional, resultando na criação do Sistema de Garantias de Direitos (SGD) da criança e do adolescente.

Assim, a legis lação brasileira para o trabalho infantojuvenil orienta-se pelos princípios estabelecidos na Constituição Federal de 1988 e do ECA, que tem como premissa, a doutrina da proteção integral à criança e ao adolescente, garantindo seus direitos com prioridade absoluta (ECA, 1990). O Brasil é signatário dos principais atos referentes à temática, destacando-se a Declaração sobre os Direitos da Criança (1923), a Declaração Universal dos Direitos Humanos (1948), a Segunda Declaração Universal dos Direitos da Criança (1959), a Convenção sobre os Direitos da Criança (1989), a Declaração de Viena (1993) e a Convenção 132 e 182 da OIT.

A Constituição Brasileira prevê a proibição de trabalho noturno, perigoso ou insalubre aos menores de dezoito anos e de qualquer trabalho aos menores de dezesseis anos, salvo na condição de aprendiz, a partir dos quatorze anos (art. $7^{\circ}$, inciso XXXIII). Contrariando este princípio legal, há um número cada vez maior de oficinas mecânicas e lava jatos que utilizam da mão de obra infantojuvenil.

E com a ratificação das Convenções 138 e 182 da OIT, que versam sobre a idade mínima de admissão ao trabalho e sobre as piores formas de trabalho infantil, respectivamente houve uma ressalva para que se aumente a idade mínima de admissão ao trabalho, considerando seu completo desenvolvimento físico e mental. A convenção 182 define o que significa piores formas, como os trabalhos prejudiciais à saúde, moral, segurança e lista 93 atividades que trazem riscos se desenvolvidas por crianças e adolescentes.

A determinação de idade limite para admissão ao trabalho, segundo estipulado pela OIT, busca preservar a permanência e continuidade do jovem no processo escolar, bem como estimular a cultura, o lazer e a preservação dos vínculos familiares.

No campo dos direitos humanos houve inegavelmente um avanço no século $\mathrm{XX}$, através de novas convenções que especificaram os direitos a serem protegidos como resposta a violações que passaram a ser supervisionada pela Organização das Nações Unidas (ONU) dentro dos Estados. Mas apesar desses avanços, a efetivação dos direitos humanos ainda se dá de forma lenta, principalmente se considerarmos o quadro da sociedade brasileira, o qual se caracteriza por desigualdades e pela exclusão econômica e social, onde as políticas públicas priorizaram os direitos civis e políticos, em detrimento dos direitos econômicos, sociais e coletivos.

Mesmo com todo esse aparato, o ECA não é suficiente para proteger os 
direitos das crianças e dos adolescentes, no que se refere, por exemplo, à inserção precoce no trabalho. De acordo com os últimos dados da PNAD (2015), no Brasil 2,7 milhões de crianças e adolescentes com idades entre 5 e 17 anos estão em situação de trabalho, 2 milhões entre 14 e 17 anos, $68 \%$ do total estão em atividades não agrícolas. No Tocantins, 21.278 de crianças e adolescentes com idades entre 5 e 17 anos estão ocupados, de acordo com a última PNAD (2015). O Estado teve a maior redução da região Norte no número de crianças e adolescentes em situação de trabalho, visto que em 2004 tinha 60.172, uma redução de $65 \%$ aproximadamente. Há um destaque para as atividades de comércio e reparação de serviços (entre elas as atividades nas oficinas mecânicas e lava jatos) com 31,4\% do total de crianças e adolescentes que estão exercendo alguma atividade, a maior taxa da região Norte e uma das maiores do Brasil.

Por trabalho infantojuvenil, entende-se o desempenho de atividades econômicas e de sobrevivência, com ou sem a finalidade de lucro, podendo ser remunerada ou não, realizadas por crianças e adolescentes com idade inferior a 16 anos, considerando a condição de aprendiz a partir dos 14 anos (FNPETI, 2018).

Uma das causas da incorporação de crianças pelo mercado tem sido a precarização das relações de trabalho, aliada ao mito do trabalho como valor ético e moral, "formativo", "escola da vida", que torna o homem "mais digno" e como prevenção da marginalidade (Alberto, Silva, Souza \& Nunes, 2010a; Pillotti \& Rizzini, 2009; Santos, 2009). A sociedade, influenciada por estes motivos, associa o "não-trabalho" à "marginalidade" e à "delinquência", corroborando com a ideia de que o trabalho é o formador por excelência das crianças e adolescentes mais pobres.

Esse tipo de pensamento implica em práticas sociais que tornam invisível o trabalho infantojuvenil, de maneira específica nas oficinas mecânicas e lava a jatos, levando-se a crer que este é um tipo de trabalho mais "brando", não exploratório e que não causa consequência alguma para as crianças e os adolescentes que desenvolvem estas atividades. Acredita-se assim que este é um trabalho que prepara para a vida.

Observando as causas, percebe-se que o fator pobreza não é exclusivo, responsável por si só, da entrada de crianças no mercado de trabalho, mas é o fator preponderante. Segundo o Ipea (2010), é mais elevado o número de crianças e adolescentes trabalhadores cujas famílias são pobres, negras e de áreas rurais. Nos grupos sociais mais vulneráveis, é cerca de quatro vezes mais provável que as crianças e adolescentes estejam em situação de 
trabalho. Segundo Arroyo (2015) o trabalho infantojuvenil "está onde está a condição mais exploradora do trabalho humano" (p. 30) e sobrevive junto aos índices constantes de sobrevivência e pobreza familiar. E essa constância do trabalho infantojuvenil anda junto ao padrão capitalista, classista, racista e sexista do trabalho que perdura e cada vez mais se sofistica.

A inserção de crianças e adolescentes em atividades de trabalho tem trazidos diversas implicações sobre sua saúde, segurança e escolarização, podendose afirmar que é um deformador da infância. As longas jornadas de trabalho, as ferramentas, os utensílios e o próprio maquinário inadequado à idade comprometem o desenvolvimento sadio de crianças e elevam o índice de mortalidade, conforme atestam relatos ao longo da história (Alberto et al, 2010a; Alberto et al, 2010b; Moura, 2009; Silva \& Pereira, 2014; Pillotti \& Rizzini, 2009).

Além disso, a situação de trabalho infantojuvenil, em que se encontraum número significativo de crianças e adolescentes em todo o mundo, traz implicações que refletem não só na dimensão mais visível, como por exemplo, a predisposição para fadiga, enfermidades e acidentes de trabalho (Forastieri, 1997), baixo nível de escolaridade, pois, no processo de escolarização desses sujeitos são comuns histórias de reprovação, repetência e defasagem escolar (Alberto et al. 2010; Cervini \& Burger, 1991; Rizzini et al, 1996; Silva \& Pereira, 2014) mas também, na dimensão latente da subjetividade, enquanto uma categoria de trabalho que imprime exclusão e sofrimento, principalmente no anonimato da informalidade (Alberto, 2002, Alberto et al, 2010a).

O trabalho penoso provoca estresse, danos físicos e prejuízos mentais; o trabalho insalubre provoca doenças e intoxicações; e o trabalho perigoso pode ocasionar acidentes ou danos à vida da criança ou adolescente trabalhador. Exemplos de locais insalubres e perigosos são minas, ambientes frios, úmidos ou com calor excessivo, galerias de esgotos, matadouros, curtumes e locais com desprendimento de poeira e resíduos como do algodão e da cerâmica. As ruas, carvoarias, pedreiras, lavouras e batedeiras de sisal, o corte de cana-de-açúcar e os depósitos de lixo são também exemplos de trabalho infantil perigoso, penoso e insalubre (Alberto et al, 2010).

O trabalho infantojuvenil em oficinas mecânicas e lava a jatos são exemplos desses trabalhos considerados penosos, insalubres e perigosos e é um fato bastante comum na nossa sociedade brasileira, principalmente nas cidades cortadas por BR. De acordo com Dias e 
Araújo (2013), o serviço (reparação de serviços automotores e motocicletas) é a segunda grande atividade em que está ocupada boa parte da mão de obra infantojuvenil na região norte, chegando a $15,9 \%$ dos que exercem alguma atividade.

Segundo Binder, Wernick, Pendoza e Almeida (2001) embora o trabalho em oficinas mecânicas constitua uma atividade cujos trabalhadores são expostos a inúmeros agentes agressores à saúde, ainda é uma atividade muito pouco estudada, tal fato pode estar relacionado à dificuldade de acesso a essas empresas. Ainda segundo os autores citados, na França, as estatísticas revelam que a incidência de acidentes nessa atividade de trabalho é mais elevada do que a média nacional, considerando que a pesquisa foi realizada com adultos e não crianças e adolescentes.

A relação de riscos de acidente nessa atividade de trabalho é enorme. O contato com substâncias químicas como óleo diesel, lubrificante, graxa e gasolina traz sérios riscos à saúde destas crianças e adolescentes. A relação de riscos de acidentes nesse ramo de atividade é extensa, incluindo desde cortes com ferramentas até acidentes de trânsito durante teste de veículos, bem como quedas relacionadas a condições de pisos, acidentes com máquinas manuais motorizadas, queda de materiais sobre o corpo, acidentes com equipamentos para elevação de veículos, queimaduras por contato com superfícies aquecidas ou por incêndios ou explosões associados ao manuseio de gasolina, ferimentos causados por ar ou água sob pressão, lesões oculares por corpo estranho, eletrocussão, dentre outros (Binder, Wernick, Pendoza \& Almeida, 2001).

No que se refere aos aspectos físicos, esse tipo de atividade concentra ruídos frequentes com efeitos indesejáveis à audição, atingindo valores em torno de 110 dB (A), níveis acima de $85 \mathrm{~dB}$ (A) implica lesão no aparelho auditivo. As exposições a vibrações por manuseio de ferramentas manuais motorizadas e às radiações ultravioleta e infravermelha em operações de corte e solda. No que se refere aos aspectos químicos, exposições às substâncias provenientes de emissões da combustão incompleta de gasolina e de óleo diesel, além das emissões de monóxido de carbono, dióxido de enxofre, óxidos de nitrogênio e hidrocarbonetos policíclicos aromáticos (Binder, Wernick, Pendoza \& Almeida, 2001).

Nos lava jatos, também existe vários agentes nocivos à saúde. $\mathrm{O}$ primeiro agente insalubre é a umidade. O uso contínuo, prolongado da água se transforma em uma situação perigosa na medida em que, a umidade é o ambiente preferido de fungos e bactérias. Desta forma, a criança e o adolescente que trabalham neste tipo de atividade estão mais sujeitos a 
desenvolverem problemas de saúde. O outro fator prejudicial à saúde presente na atividade de lavagem de veículos é a utilização de produtos químicos, os shampoos, silicones, desengraxantes e óleos usados na lavagem e limpeza dos automóveis contém em suas composições substâncias químicas prejudiciais à saúde. $\mathrm{E}$ os jovens ainda não têm um organismo tão resistente quanto o de um adulto, desta forma, o contato constante destes químicos é muito mais danoso em um organismo em desenvolvimento do que em um adulto (Fernandes, 2011).

De uma série de implicações sociais indesejáveis do trabalho infantojuvenil, a mais grave é o prejuízo que o trabalho causa à educação (Alberto et al, 2010; Alberto \& Santos, 2011; Arroyo, 2015; Silva \& Pereira, 2014). A escola desempenha um papel importante na futura capacitação, socialização e na abertura de horizontes dos jovens. Assim, a escola acaba tendo uma importância muito maior para o desenvolvimento cognitivo das crianças. $\mathrm{O}$ nível de escolaridade e a qualidade do ensino constituem-se pré-requisitos para a entrada no seletivo mercado de trabalho (Alberto et al, 2010a, Alberto \& Yamamoto, 2017). Desse modo, não se pode admitir que lugar de criança seja no trabalho. Ao contrário, lugar de criança é na escola, com uma educação de qualidade.
A partir da perspectiva sóciohistórica, a intervenção pedagógica realizada pela escola é de extrema importância na construção dos processos psicológicos dos sujeitos. É sobretudo na escola, cuja função é a instrução deliberada, que vai ativar o desenvolvimento do sujeito. Nesse sentido, a sistematização presente na escola cria estruturas e a interação e orientação entre os sujeitos nesse ambiente, promove o desenvolvimento mental (Alberto et al, 2010a).

Vygotski (2009) usa o conceito de Zona de Desenvolvimento proximal que dá a ideia de uma área potencial de desenvolvimento da criança, tal conceito é definido como sendo a distância entre o nível atual de desenvolvimento, que contempla a capacidade de resolução atual da criança, e o nível de desenvolvimento potencial, que é determinado através da resolução de problemas com a ajuda de professores e/ou colaboração de pares mais capazes.

O que implica conceber a educação como transmissão e aprendizagem a partir da relação com esses outros, possibilitando o desenvolvimento do sujeito. Segundo Alberto e Santos (2011) dentro do espaço escolar, a zona de desenvolvimento escolar é estimulada tendo em vista a interação entre os pares e o professor que constitue m elementos mediadores em que se desenvolvem os processos de aprendizage m 
e a instrução formal, que está relacionado à disciplina formal enquanto espaço peculiar em que se concretiza a influência da aprendizagem sobre o desenvolvimento.

Além disso, o trabalho infantojuvenil é uma violação dos seus direitos enquanto pessoa humana, retirathes a dignidade, a possibilidade de brincar, de estudar, de se alimentar, de ter um lar, não tem acesso à aspectos importantes e imprescindíveis ao seu completo desenvolvimento físico, mental, moral, espiritual e social, como apregoa a Constituição Federal e o ECA (1991). De acordo com Alberto et al (2010a), é uma violação ao pleno desenvolvimento humano e social, ao tirar-lhes as oportunidades para a educação, para a aquisição de capital cultural e para uma inserção social digna futuramente.

Nesse sentido, a importância em se abordar essa problemática está relacionada à necessidade de apresentar contribuições empíricas sobre a relação do trabalho infantojuvenil com o desenvolvimento desses sujeitos e com o processo de escolarização de crianças e adolescentes.

\section{Materiais e métodos}

\section{Amostra}

Para o desenvolvimento desta pesquisa, primeiramente, foi feito uma territorialização na cidade para identificação das oficinas mecânicas e lava a jato. $\mathrm{O}$ que nos permitiu contabilizar 20 oficinas mecânicas e 5 lava a jatos na cidade. Desse total, foram encontrados crianças e adolescentes trabalhando em 4 oficinas mecânicas e 1 lava a jato. A amostra foi composta por 10 adolescentes, sendo 5 que trabalhavam nas oficinas mecânicas e 5 que trabalhavam no lava a jato.

\section{Coleta de dados e tratamento}

Para a obtenção dos dados, foi aplicado um questionário aos sujeitos que se encontravam em situação de trabalho nas oficinas mecânicas e no lava a jato. As questões versavam sobre o perfil biossociodemo gráfico, "Família", "Atividade de trabalho", "Escolaridade", "Riscos" e "Perspectivas de Futuro".

Após aplicação do questionário, foi feito leitura e releitura destes, para cuidadosa identificação e categorização das respostas. Para análise dos dados utilizo u-se o SPSS, um software para contagem de frequências e percentuais. Após, construção de um banco de dados para tratamento dos dados.

\section{Resultados e discussão}

Foram entrevistadas 10 crianças e adolescentes, sendo que $50 \%$ delas foram encontradas trabalhando em oficinas 
mecânicas e $50 \%$ no lava a jato. Em relação àfaixa etária desses sujeitos, variava de $11 \mathrm{a}$ 17 anos. Porém a idade predominante na pesquisa foi de 17 anos, totalizando $60 \%$ dos entrevistados. Tais dados confirmam os resultados da última PNAD que consta mais de 2 milhões de adolescentes em situação de trabalho no Brasil.

De acordo com a Constituição Federal e o ECA, a partir dos 14 anos, na condição de aprendiz, é permitido o trabalho. Nesses casos, o trabalho não pode ser noturno, perigoso ou insalubre, e não deve prejudicar a frequência e muito menos o rendimento escolar do adolescente. No entanto, dos 10 sujeitos entrevistados, nenhum estava legalmente empregado e seguem sendo exploradas sem a proteção que está prevista na Constituição Federal, no ECA e na Lei do Aprendiz. Dessa forma, a atividade exercida pelos adolescentes não se configurava na condição de aprendiz. Aliado a isso, as atividades desenvolvidas em lava a jatos e oficinas mecânicas configuram como uma das piores formas de trabalho infantojuvenil de acordo com a Convenção 182 da OIT.

Nessa pesquisa houve unanimidade na questão do sexo e do lugar onde moram os sujeitos. Todos os entrevistados são do sexo masculino e vivem na zona urbana. Já relacionado à etnia, a maioria se identifica como negro. Tais dados também são corroborados por outras pesquisas relacionadas à predominância do sexo masculino nos serviços de comércio e reparação (Alberto et al, 2010; Arroyo, 2015; Dias \& Araújo, 2013; Silva \& Pereira, 2014), bem como a predominância de crianças e adolescentes negros exercendo alguma atividade de trabalho (Alberto et al, 2009; Alberto et al, 2010a; Alberto et al, 2010b; Arroyo, 2015; Dias \& Araújo, 2013; Silva \& Pereira, 2014).

No que se refere à família destes sujeitos, $50 \%$ dos entrevistados respondeu que seus pais trabalham, entre as profissões dos pais a maioria trabalha como pedreiro, num total de $40 \%$ dos entrevistados. E em relação às mães, $60 \%$ respondeu que elas também trabalham, $33,3 \%$ como domésticas e 33,3\% em serviços gerais (limpeza). Nota-se que há uma predominância de mães que trabalham, em relação aos pais que trabalham. Esse dado se explica devido ao fato de $50 \%$ dos entrevistados responderem que ou não moram com o pai, ou não o conhece. A maioria dos entrevistados responderam que suas familias vivem com uma renda mensal de 1 salário e meio à 2 salários, a renda per capita nessas famílias era em torno de 155 reais. Tais dados também são encontrados nas pesquisas de Alberto et al (2010a), Alberto et al (2010b), Alberto et al (2011), Silva e Pereira (2014). Considerando que algumas famílias tinham de 6 a 8 pessoas 
morando juntas, esse valor per capita é ainda menor.

No que se refere ao trabalho realizado pelos adolescentes, 50\% trabalhavam lavando, enxugando e encerando carros. Os outros 50\% dos sujeitos realizavam troca do óleo do veículo, troca e remenda de pneu, revisão nos veículos. Segundo Binder, Wernick, Pendoza e Almeida (2001) este tipo de atividade traz graves prejuízos à saúde desses sujeitos, e todos estão expostos diariamente. Há a presença de uma série de riscos, físicos, biológicos, químicos, ergonômicos, psicológicos e sociais (Alberto et al, 2010a; Alberto et al, 2010b). O contato com substâncias corrosivas e a pele ainda em processo de desenvolvimento, faz com que as crianças e adolescentes sejam menos resistentes a intoxicações dos produtos, aliado a isso, $\mathrm{o}$ ambiente muitas vezes úmido e insalubre que provoca outras doenças nos sujeitos (Alberto et al, 2010a; Alberto et al, 2010b; Binder, Wernick, Pendoza \& Almeida, 2001; Fernandes, 2011).

Uma outa questão que se levanta é o grande risco de acidentes de trabalho em crianças e adolescentes que trabalham. Segundo Brito (2017), com informações advindas do Departamento de Vigilância em Saúde Ambiental e Saúde do Trabalhador, desde 2007 quase 40 mil crianças e adolescentes se acidentaram enquanto exerciam alguma atividade de trabalho. Desses, mais da metade foram ocorrências classificadas como graves, e inclui amputação de membros superiores e/ou inferiores e até mesmo morte.

Alberto et al (2010a) também afirma, em pesquisa feita, que todas as atividades desenvolvidas por crianças e adolescentes afetam o corpo e provocam sensações que se expressam no sofrimento no e do corpo. Cada atividade desencadeia um sofrimento específico, relacionado às exigências de esforço físico e desgastes provocados pela atividade que desenvolve $m$ e pela postura do corpo. Esse sofrimento se manifesta por cansaço ou dores no corpo, pernas cansadas, dormentes, músculos doloridos, dores na coluna, nos braços.

Também identificado nessa pesquisa, ao serem perguntados sobre o que mais gostavam no trabalho, grande parte dos sujeitos disseram que não gostavam de nada no seu serviço, e quando identifica vam a atividade que mais gostava, $60 \%$ responderam que era o mais fácil de se fazer no seu trabalho. Com relação ao que menos gostavam de fazer no seu trabalho, 33, 3\% responderam que é lavar carros, porque é o mais difícil de fazer para a maioria $(57,1 \%)$. A metade deles disseram que se sentem cansados/exausto após um dia de trabalho e aliviados por terem acabado o trabalho, conforme Alberto et al (2010a). O turno de trabalhos deles, por unanimidade, é o turno 
diurno. A metade deles respondeu que em suas horas vagas saem com os amigos ou ficam em casa.

Quando perguntado sobre o porquê de não gostarem da atividade, a maioria dos sujeitos disseram que "só o dono da oficina ganha dinheiro, o serviço é feito de graça", "dá muito trabalho", "fico sem tempo de me divertir", "é muito chato" (sic). Dado corroborado em pesquisa desenvolvida pelo FNPETI (s/d), em que boa parte das crianças e adolescentes que exerciam atividade não recebiam dinheiro. Tais falas nos revelam, entre outros aspectos, que o trabalho infantojuvenil é inadequado para o completo desenvolvimento desses sujeitos, cuja aprendizagem, sonhos, brincadeiras e proteção são substituídos por uma rotina de responsabilidade, expondo-os a diversos riscos, violando os seus direitos mais elementares.

No que diz respeito à escolaridade, grande parte dos sujeitos entrevistados estavam estudando, embora $30 \%$ deles estivesse fora da escola. Um dado que sobressaiu foi que $70 \%$ deles já foram reprovados na escola. Artes e Carvalho (2010) destacam que o trabalho infantojuvenil tem sido considerado $\mathrm{o}$ principal responsável pelo mau desempenho desses sujeitos. Vários autores (Alberto et al, 2010a; Alberto et al, 2010b; Arroyo, 2015; Artes \& Carvalho, 2010; Silva \& Pereira, 2014) corroboram com esse achado, as crianças e adolescentes que trabalham sofrem uma defasagem escolar, que podem chegar a nove anos. O cansaço físico compromete o estudo desses sujeitos, com longas jornadas de trabalho, também dificultando a aprendizagem da escrita e da leitura (Alberto et al, 2010a; Alberto at al, 2010b).

A grande maioria dos sujeitos entrevistados responderam que suas famílias participam de algum programa de assistência do governo. O que demonstra a imensa pobreza que grande parte da população vive. E são esses sujeitos, que desde a infância são condenadas a sobreviver do trabalho, terão negados o seus direitos, porque reprovam na escola, não terão direito ao diploma, porque precisam trabalhar. De acordo com Arroyo (2015), esses mesmos sujeitos não terão direito a entrar no mercado de trabalho porque foram condenadas desde a infância a sobreviver nessa relação trabalho-estudo e condenadas que são, pela lógica segregadora escolar, que só reprova.

\section{Considerações finais}

A partir da pesquisa realizada, o trabalho infantojuvenil nas oficinas mecânicas e nos lava a jatos é realizado na sua totalidade por meninos, negros, com idades entre 14 e 17 anos de idade, que pertencem a famílias de classe baixa e que tem pouco incentivo à educação. Outro 
detalhe importante que notamos na pesquisa, está relacionado aos tipos de atividades que eles exercem nesse trabalho, que levam a um cansaço físico do corpo, o contato com substâncias tóxicas, o que contribui para seu desgaste físico $\mathrm{e}$ psicológico, causando sérios danos a esses sujeitos.

Outro aspecto que prevaleceu nos dados foi a defasagem escolar da maioria dos sujeitos entrevistados, o que nos leva a questionar até que ponto a escola está preparada para receber esses sujeitos? Qual o compromisso social da escola? Como ignorar essas vivências do trabalho infantojuvenil da agenda escolar? Temos um contingente de crianças e adolescentes trabalhadores, que ao entrarem na vida adulta, permanecerão na mesma precariedade e pobreza de quando criança.

O que temos atualmente é que a política de educação até garante o acesso

\section{Referências bibliográficas}

Alberto, M. F. P. (2002) Dimensão Subjetiva do Trabalho Precoce de Meninos e Meninas em Condição de Rua em João Pessoa (PB). 2002. 305f. Tese (Doutorado em Sociologia). Universidade Federal de Pernambuco, Recife.

Alberto, M.F.P. et al (2009). Trabalho infantil doméstico: perfil biosócioeconômico e configuração da atividade no município de João das crianças e adolescentes, através da matrícula, mas não a permanência e a conclusão de todas as fases do ensino no tempo correto. Nem mesmo a política de assistência tem sido eficaz no que concerne às famílias, para que tenham uma renda que sustente a família. Ou seja, a Rede, que são as instituições responsáveis pelo atendimento e proteção dos direitos, não tem funcionado adequadamente, e os direitos das crianças e dos adolescentes continuam cotidianamente sendo violados.

O que se percebe é que há uma continuação, um círculo vicioso na precariedade e exploração do trabalho que vai da infância à vida adulta. De acordo com Arroyo (2015), são histórias anunciadas da exploração do trabalho adulto pelo capital. Por isso não é possível erradicar/eliminar o trabalho infantojuvenil sem que possa superar a exploração do trabalho adulto.

Pessoa, PB. Cadernos de Psicologia Social do Trabalho, vol. 12, n. 1, pp. 57-73.

Alberto, M.F.P.; Silva, A.C.S.; Souza, G.P. \& Nunes, T.S. (2010a) O trabalho infantil na rua. Cadernos de Psicologia Social do Trabalho, vol. 13, n. 1, pp. 59-71.

Alberto, M.F.P. et al. (2010b) Mapeamento do trabalho infantil na Paraiba: um contexto de desenvolvimento para crianças e adolescentes pobres. In LUNA, V. L. R.; NASCIMENTO, 
Z. A. (Org.). Desafios da psicologia contemporânea. João Pessoa: UFPB.

Alberto, M. F. P. \& Yamamoto, O.H. (2017). Quando a educação não é a solução: política de enfrentamento ao trabalho Infantil. Temas em Psicologia, Vol. 25, n 4, 16771691. DOI: 10.9788/TP2017.4-10Pt

Ariès, P. (1995) História social da criança e da família. 2.ed.) Rio de Janeiro: Guanabara.

Arroyo, M. (2015) A infância repõe o trabalho na agenda pedagógica. In Arroyo, M. G., Viella, M. A. L., Silva, M. R. S. (Orgs.). Trabalho infância: exercícios tensos de ser criança: haverá espaço na agenda pedagógica?. Petrópolis, RJ.

Artes, A. C. A., Carvalho, M. P. C. (20100. O trabalho como fator determinante da defasagem escolar dos meninos no Brasil: mito ou realidade?. Cadernos Pagu (34), janeiro-junho de 2010:41-74.

Binder, M.C.P; Wernick, R.; Pendoza, E.R. \& Almeida, I.M. (2001). Condições de Trabalho em Oficinas de Reparação de Veículos Automotores de Botucatu (São Paulo). Informe e Epidemiologia do Sus. 10 (2): 67-79.

Brito, D. (2017). Brasil registra aumento de trabalho infantil entre crianças de 5 a 9 anos. Recuperado de http $/ /$ agenciabrasil.ebc.com.br/dire itos-humanos/noticia/201706/brasil-registra-aumento-decasos-de-trabalho-infantil-entre

Cervini, R. \& Burger, F. (1991) O menino trabalhador no Brasil urbano dos anos 80. In Cervini, R. \& Burger, F. $O$ trabalho e a rua: crianças $e$ adolescentes no Brasil urbano dos anos 80. São Paulo: Cortez, pp. 1746; 227-242.

Convenção $n^{\circ} 138$, aprovada em 27 de Junho de 1973, promulgada no Brasil pelo decreto 4.134 de 15 de Fevereiro de 2002. Dispõe sobre a idade mínima de admissão a emprego. Recuperado em 15 de Abrilde 2014, de http://portal.mte.go v.br/data/files/FF80 80812BAFFE3B012BCA906FCD116 5/cv_138.pdf.

Convenção $n^{\circ}$ 182, aprovada em 17 de Junho de 1999, promulgada no Brasil pelo decreto 3.597 de 12 de Setembro de 2000. Dispõe sobre a proibição das piores formas de trabalho infantil e a ação imediata para sua eliminação. Recuperado em 15 de Abril de 2014, de http//www.tjpb.jus.br/wpcontent/uploads/ 2012/05/Convencaon.-182-e-Decreto-6481.pdf.

Convenção sobre os Direitos da Criança. (2002) Rio de Janeiro: Save in the Children.

Constituição da República Federativa do Brasil. Brasilia: Casa Civil (1988). Recuperado de http //www.planalto.gov.br/civil_03 /Constituicao/Constitui\%C3\%A7ao $\underline{\text { htm }}$

Del Priore, M. (2007). História da criança no Brasil. 6.ed. São Paulo:

Contexto.

Dias, J. C., Araújo, G. S. (2013) $O$ trabalho infantil na Região Norte do brasil: Uma leitura a partir dos microdados do censo Demográfico de 2010. Relatório Final. Brasília.

Estatuto da Criança e do Adolescente/ Lei 8.069 (2005).Secretaria Especial dos Direitos Humanos; Ministério da Educação. Brasîlia: MEC. 
IBGE. (2015) Pesquisa Nacional por Amostra de Domicílio, PNAD: 2014-2015. Rio de Janeiro: IBGE.

Data de Submissão: 28/05/2018

Data de Aceite: 23/09/2018

IPEA.(2010) Trabalho infantil no Brasil: rumo à erradicação. [s.l.]: [s.e.].

Fernandes, S. V. (2011) .Trabalho infantil em lavarápidos. Recuperado de http $/ /$ erradicacaotrabalhoinfantil.bl ogspot.com.br/2011/05/lavarapidos-uma-das-piores- formasde.html. 